\title{
Traditional Pit Growing Method of Diyarbakir Watermelon
}

\author{
Vedat Pirinc, \\ Dicle University, Faculty of Agriculture, Department of Horticulture, \\ 21280 Diyarbakir, Turkey \\ E-mail:vedpir@dicle.edu.tr \\ Erhan Akalp \\ Dicle University, Faculty of Agriculture, Department of Horticulture, \\ 21280 Diyarbakir, Turkey
}

\begin{abstract}
Watermelon, it is known as the symbol of Diyarbakır province and is identified as a specific vegetable. It is not only the symbol of the city, but also has an important position in cultural and the economic life of the region. In the study, it is aimed to introduce the genotypes of Diyarbakir watermelon and the growing of pit method that is specific to Diyarbakır watermelon.

There are 5 different types of watermelon known as Diyarbakır watermelon which are described and explained from past to present. These types are; Beyaz K1s, Kara K1s, Pembe, Ferik Pasa and Surme genotypes. Today, Surme is the only type that is cultivated among these types. The watermelon known as Diyarbakır watermelon is Surme type and its growing is still being done. The most important characteristics of this type are its delicious and large size. Watermelons of $60-75 \mathrm{~kg}$ in the past seem to have lost their originality today. It is no longer possible to find other types of watermelon expect Surme type. It has been observed that the cultivation of this type, which the festivals are organised as the name of Watermelon, has been decreasing day by day. And largeness and the delicious are the most important characteristics of Diyarbakir watermelon due to the special growing method. This method of growing is called "pit growing method". However, this method can not be used today.

With this study, it is aimed to introduce the Diyarbakır watermelon types with their basic characteristics and to draw attention to the re-growing of these types that have been disappearing. Thus, it is thought that the growing method of Diyarbakır watermelon will help to carry the watermelon cultivation again and apply it. It is also expected to provide solutions to the problems of growers and other watermelon cultivation.
\end{abstract}

Keywords: Diyarbakır, Pit Watermelon Growing, Surme

DOI: $10.7176 / J S T R / 5-12-11$

\section{Geleneksel Diyarbakır Kuyu Karpuzculuğu}

Özet

Karpuz, Diyarbakır'a özgü bir sebze olarak anılmakta ve ilin sembolü olarak özdeşleşmiş durumdadır. Şehrin sembolü olmanın ötesinde yörenin kültürü ve ekonomik hayatında önemli bir konuma sahiptir. Çalışmada, Diyarbakır karpuzu olarak anılan genotiplerin ve Diyarbakır karpuzuna özgü kuyu karpuzu yetiştiriciliğinin tanıtılması amaçlanmıştır.

İlde Diyarbakır karpuzu olarak geçmişten günümüze kadar anlatılan ve bilinen 5 farklı karpuz tipi bulunmaktadır. Bu tipler; Beyaz Kış, Kara Kış, Pembe, Ferik Paşa ve Sürme tipleridir. Bu tiplerden yetiştiriciliği yapılan sadece Sürme tipidir ve günümüzde, "Diyarbakır karpuzu” olarak bilinmektedir Sürme karpuzunun en önemli özelliği; iriliği ve lezzetli oluşudur. Geçmişte 60-75 kg'lık gelen karpuzlar bugün eski özelliğini yitirmiş görünmektedir. Sürme tipi dışında diğer karpuz tiplerini bulmak artık mümkün görünmemektedir. Adına karpuz festivalleri düzenlenen Sürme tipinin yetiştiriciliğinin her geçen gün azaldığ 1 gözlemlenmiştir. Ayrıca, Diyarbakır karpuzunu iri ve lezzetli oluşunun en önemli 
nedeni ise yetiştirme yöntemi olduğu bilinmektedir. Bu yetiştirme yöntemine ise "kuyu karpuzculuğu" olarak isimlendirilmektedir. Ancak bu yöntem bugün kullanılmamaktadır.

Yapılan bu çalışma ile Diyarbakır karpuz tiplerini temel özellikleri ile tanıtmak ve kaybolmaya yüz tutmuş bu tiplerin tekrar yetiştiriciliğinin yapılmasına dikkat çekilmek istenmiştir. Böylece Diyarbakır karpuzuna ait yetiştirme yöntemi olan kuyu karpuz yetiştiriciliğini tekrar gündeme taşımak ve uygulanmasına yardımcı olacağı düşünülmektedir. Ayrıca, çiftçilere ve diğer karpuz yetiştiriciliğindeki sorunlara çözüm sunacağı beklenmektedir.

Anahtar Kelimeler: Diyarbakır, Kuyu Karpuzculuğu, Yetiştiricilik, Sürme

\section{GİRIŞ}

Orijini ve Tarihçesi

Karpuz, Cucurbitaceae familyasının Citrullus cinsine bağlı tek yıllık bir kültür bitkisi olup gen merkezi Afrika'dır (Decoteau, 2000). Karpuzun ne zaman kültüre alındığı tam olarak bilinmemekle birlikte, en az 4000 yıl öncesine dayandırılmaktadır (Sauer, 1993; Van Wyk ve Gericke 2000). Karpuz kültürüne ilişkin en eski bulgular, tarih öncesi devirlere ait olup, eski Mısır resimlerinden elde edilmiştir. İlk olarak Misır ve Hindistan'da başlayan kültürü, daha sonra tüm dünyada yayılmıştır. Kültür çeşitlerinin Mısır ve Suriye üzerinden Anadolu'ya ve buradan da 15. yüzyıldan itibaren Avrupa'ya yayıldığı bildirilmektedir (Kütevin ve Türkeş, 1985; Ekinci, 1972). Amerika'ya ise Avrupalı koloniler vasitasıyla götürüldüğüne inanılmaktadır. Bugün ise; Rusya'nın ılıman bölgeleri ile Çin ve Japonya’ya kadar yayılmış olan, oldukça önemli bir sebze türüdür (Mohr, 1986).

Diyarbakır Karpuzu'nun tarihçesi ile ilgili olarak detaylı bilgiler bulunmamakla birlikte, şöyle bir olay anlatılır: "Lokman hekim, ölüme derman bulmak için yollara düşer. Bu yolculuğunda Diyarbakır'a da uğrar. Urfa kapısından içeri girer ve zerzevatçılar meydanına gelir. Orada gördüğü, uzun, iri patlıcanlar dikkatini çeker (Bu patlıcanlar, günümüzde "Şeyhkent" olarak bilinen yöresel çeşittir). Hayret ederek; "Bu patlıcanlarl yiyorlar da nasll hasta olmuyorlar" der. Biraz daha yürüyüp de üst üste ylğll iri karpuzlarl görünce: "Yemekten sonra bu karpuzlardan bol bol yiyorlar, hastalanmaylşlarının sebebi budur” demiş” (Beysanoğlu, 1972).

Cucurbitaceae familyasının tropik ve subtropik bölgelerde yaygın, 90 cinsi ve 700 kadar türü vardır (Yaltırık ve Efe, 1989). Ülkemizde ise, 3 cins ve 8 türü doğal yayılış gösterir (Seçmen ve ark. 2000). Cognfaux ve Harms ile Shimotsuma, Citrullus cinsine ait aşağıdaki beş karpuz türünün bulunduğunu bildirmişlerdir (Mohr, 1986):

Citrullus lanatus (Thunb.) Matsuma and Nakai

Citrullus colocynthis (L) Schrad

Citrullus ecirrhosus Cogn.

Citrullus naudinianus (Sond.) Hook

Citrullus fistulosus

Citrullus lanatus (Thunb.) Matsum and Nakai, orijini Güney Afrika olan tek yıllık bir bitkidir. Ülkemizde özellikle İç Batı, Güney ve Güneydoğu Anadolu'da kültürü yapılmaktadır (Seçmen ve ark. 2000). Bu türün iki alttürü bulunmaktadır; "ssp. lanatus"ve "ssp. vulgaris". Bu tür, büyük ve derin olarak bölünmüş 3 veya 5 loblu ya da lobsuz yapraklara sahiptir. Çiçekleri, açık sarı renkli ve genellikle monoiktir. Bazı eski çeşitlerde andromonoik çiçek yapısına rastlamak da mümkündür. Çiçek yapısından dolayı yabancı tozlanır ve tozlanma arılarla gerçekleşir. Meyve büyüklüğü, orta iri (3-5 kg) ile iri (15-20 $\mathrm{kg}$ ) arasında değişir. Son yıllarda, sera yetiştiriciliğine elverişli, meyveleri 0.5-1.0 kg ağırlığında olan çeşitler geliştirilmiştir. Meyvelerinde su içeriği yüksek olup, et rengi kırmızı, sarı, pembe ve yeşil olabilir. Tohumları oval veya uzundur. Tohum rengi beyazdan kahverengi-siyaha kadar farklı tonlarda olabilir. Tohum irilikleri de çeşitlere göre farklılık göstermektedir. Üretimi yapılan çeşitlerin dâhil olduğu bu türün kromozom sayısı, 2n=22'dir.

\section{Besin İçeriği}

Karpuz iştah açıcı ve serinletici bir yaz sebzesidir. İçinde bulunan bol su ile bu görevi yerine getirir. Bu yüzden eski devirlerden beri sevilerek tüketilen bir sebze olmuştur. Oldukça yüksek oranda şeker içerir. Anadolu karpuzları, Orta Asya, Hindistan ve İran karpuzları karşısında daha az tatlı olmalarına rağmen, yine de \%5-8 arasında şeker oranına sahiptir. Şekerin büyük çoğunluğu glikoz formundadır. Bu bakımından şeker kana çabuk karışır. Yaptığımız çalışmalarda, Diyarbakır karpuzundaki şeker oranı ise \%8-10'dur. Karpuzda A, B B $_{2}, B_{6}, B_{12}$ vitaminleri yanında önemli miktarda $C$ vitamini vardır. Karpuzun 100 gramında, B vitamini 0.006-0.05 g, C vitamini 0.7-7.0 mg civarında bulunur. Ayrıca, $0.5 \mathrm{~g}$ protein, 
0.002 g yağ içerir. Madensel maddelerin miktarı fazla yüksek değildir (Günay, 1992).

Karpuz daha çok taze olarak yenir. Bununla beraber bazı Orta Asya ülkelerinde suyundan bira ve şarap yapılır. Ülkemizde ve diğer bazı ülkelerde, kabuklarından veya meyve etinden turşu ve reçel yapılır. Küçük meyveleri ve yaprakları pişirilerek yenir. Halk arasında, göz ağrılarında, mide rahatsılıklarında, solucan düşürmede, balgam söktürmede, ağız kokusunun giderilmesinde ve baş ağrısına karşı karpuzdan yararlanılır. Ayrıca karpuz tohumları kullanılarak hazırlanan bir karışım kozmetikte kullanılmaktadır. Acı olan yabani bir formu ilaç olarak kullanılmaktadır (Günay, 1992; Sauer, 1993; Van Wyk ve Gericke 2000).

\section{Karpuzun Ekonomik Önemi}

Bitkisel üretimde sebzeler ekili alan ve üretim miktarı bakımından önemli bir konuma sahiptir. Sebzeler içerisinde ise meyvesi yenilen sebzeler yani domates, karpuz, kavun, biber ve patlican gibi sebzelerin üretim değerleri yüksek boyutlardadır. Türkiye'de 2017 verilerine göre (Çizelge 1), sebze ekim alanı 7.982.650 da olup, aynı yıl içerisindeki toplam sebze üretimi ise 28.572.251 tondur. Sebze üretimi içinde karpuz üretimi ise küçümsenemeyecek boyuttadır (Anonim,2019).

Karpuz yetiştiriciliği 2017 verilerine göre, 904.884 da'lık alanda yapılmakta ve 4.011.313 ton civarında karpuz üretimi gerçekleşmektedir.

Türkiye'de karpuz, sebze üretimi içerisinde gerek ekim alanları gerekse de üretim bakımından domatesten sonra ikinci sırada yer almakta ve hemen hemen tüm illerimizde üretimi yapılmaktadır. Yıllara göre değişmekle birlikte ülkemizde toplam sebze üretiminin \%15-20' i karpuz oluşturmaktadır (Anonim, 2019).

Ülkemizdeki karpuz üretiminde; Adana, Antalya, İzmir, Diyarbakır, Şanlıurfa ve Mardin illeri ilk sıralarda yer almaktadır (Çizelge 2). İlk 3 ilde örtüaltı tarımında da karpuz üretiminin yapıldığı dikkate alınırsa Diyarbakır ilinin karpuz üretim miktarı küçümsenemeyecek boyuttadır. Diyarbakır ilinin karpuzla özdeşleşmesi ve geçmişten beri karpuz üretiminin yapıldığı dikkate alınırsa karpuzun bu il için özel bir öneme sahip olduğu görülecektir.

Çizelge 1. Türkiye'de bazı sebzelerin üretim miktarı (ton)

\begin{tabular}{|c|c|c|c|c|c|}
\hline Y1llar & Domates & Karpuz & Soğan(kuru) & Hiyar & Kavun \\
\hline 2015 & 12615000 & 3918558 & 1879189 & 1882636 & 1719620 \\
\hline 2016 & 12600000 & 3928892 & 2120581 & 1811681 & 1854356 \\
\hline 2017 & 12750000 & $\mathbf{4 0 1 1 ~ 3 1 3}$ & 2175911 & 1827782 & 1813422 \\
\hline
\end{tabular}

Anonim, 2019

Çizelge 2. Karpuz üretiminin yoğun olduğu iller

\begin{tabular}{|c|c|c|}
\hline İl Adı & $\begin{array}{c}\text { Ekilen } \\
\text { Alan(da) }\end{array}$ & $\begin{array}{c}\text { Üretim } \\
\text { (ton) }\end{array}$ \\
\hline Adana & 120.206 & 831.684 \\
\hline Antalya & 81.613 & 487.794 \\
\hline İzmir & 43.239 & 196.544 \\
\hline Diyarbakır & $\mathbf{4 3 . 3 8 2}$ & $\mathbf{1 6 3 . 2 1 8}$ \\
\hline Şanlıurfa & 37.856 & 130.957 \\
\hline Mardin & 31.405 & 93.139 \\
\hline \multicolumn{2}{|c|}{ Anonim, 2019 } \\
\hline \multicolumn{2}{|c|}{}
\end{tabular}

\section{DIYYARBAKIR' DA KARPUZ ÜRETIMI}

Karpuzu ile ünlü ilimiz Diyarbakır'da bitkisel üretimde karpuz önemli bir konuma sahiptir. İlin tarımsal özellikleri dikkate alındığında gerek ekili alan ve gerekse de ürün yelpazesi oldukça geniştir. Diyarbakır ilinde ilçeler bazında sebze üretimi Çizelge 3' te verilmiştir. İlde Kavun, Karpuz, Domates ve Biber tarımı ağırlıklı yapılmaktadır. Bu sebzelerin üretimi özellikle Merkez, Bismil, Çınar, Ergani, Silvan, Çermik ve Çüngüş’te yoğunlaşmaktadır.

Karpuz yetiştiriciliği Diyarbakır'da oldukça önemli bir konuma sahiptir. Üretim ve ekili alan bakımından da sebzeler içerisinde öncü bir tür olarak karşımıza çıkmaktadır. 
Karpuz gerçekten de ilin tarımsal yapısında ve kültüründe ayrı bir öneme sahiptir. Bu durum yıllardır geleneksel olarak sürdürülen karpuz yarışması ve festivalleri ile güncelliğini korumuştur. Diyarbakır'da, 163.218 ton karpuz üretimi yapılmaktadır (Çizelge 4). Bu üretimin önemli bir kısmını ticari çeşitler oluştururken yerli tiplerden ise başta Sürme tipi olmak üzere yerli tipler oluşturmaktadır. Diyarbakır için karpuzun ekonomik ve kültürel boyutu, yıllardan beri önemini korumuştur.

Uzun yıllardan beri düzenlenen "Karpuz Festivali”, hâlâ büyük ilgi görmektedir. Bu festivalde, karpuz üreticileri yetiştirdikleri karpuzları sergilerler ve büyüklük esasına göre sıralamaya girenlere ödül verilir. Bu karpuzlar, daha çok Dicle Nehri kıyısında bulunan köylerin bostanlarında yetiştirilir.

Çizelge 3. Diyarbakır' da bazı sebzelerin İlçelerdeki üretimi

\begin{tabular}{|c|c|c|c|c|c|c|c|c|c|c|}
\hline \multirow[t]{2}{*}{ İlçe Adı } & \multicolumn{2}{|c|}{ Domates } & \multicolumn{2}{|c|}{ Hıyar } & \multicolumn{2}{|c|}{ Biber } & \multicolumn{2}{|c|}{ Kavun } & \multicolumn{2}{|c|}{ Karpuz } \\
\hline & $\begin{array}{c}\text { Ekilen } \\
\text { Alan } \\
\text { (da) }\end{array}$ & $\begin{array}{l}\text { Üretim } \\
\text { (ton) }\end{array}$ & $\begin{array}{c}\text { Ekilen } \\
\text { Alan } \\
\text { (da) }\end{array}$ & $\begin{array}{c}\text { Üretim } \\
\text { (ton) }\end{array}$ & $\begin{array}{c}\text { Ekilen } \\
\text { Alan } \\
\text { (da) }\end{array}$ & $\begin{array}{c}\text { Üretim } \\
\text { (ton) }\end{array}$ & $\begin{array}{c}\text { Ekilen } \\
\text { Alan } \\
\text { (da) }\end{array}$ & $\begin{array}{c}\text { Üretim } \\
\text { (ton) }\end{array}$ & $\begin{array}{c}\text { Ekilen } \\
\text { Alan } \\
\text { (da) }\end{array}$ & $\begin{array}{l}\text { Üretim } \\
\text { (ton) }\end{array}$ \\
\hline Bismil & 1.550 & 8.025 & 627 & 2.348 & 960 & 1.205 & 1.500 & 3.000 & 4.750 & 19.000 \\
\hline Çermik & 800 & 4.046 & 677 & 2.436 & 1.370 & 2.740 & 900 & 2.340 & 1.500 & 4.500 \\
\hline Çınar & 1.500 & 5.543 & 1.450 & 3.625 & 1.380 & 2.680 & 3.000 & 10.500 & 13.500 & 67.500 \\
\hline Çüngüş & 3.700 & 7.272 & 1.207 & 2.654 & 400 & 500 & - & - & - & - \\
\hline Dicle & 460 & 1.360 & 200 & 600 & 925 & 1.850 & 2.429 & 3.886 & 212 & 466 \\
\hline Ĕğil & 88 & 408 & 48 & 279 & 14 & 17 & 1.000 & 2.790 & 1.800 & 5.859 \\
\hline Ergani & 9.035 & 28.012 & 952 & 1.368 & 2.400 & 3.320 & 3.601 & 9.009 & 11.000 & 31.900 \\
\hline Hani & 1.310 & 2.969 & 650 & 1.300 & 190 & 279 & 600 & 960 & 800 & 2.400 \\
\hline Hazro & 645 & 1.631 & 265 & 538 & 270 & 392 & 1.250 & 2.000 & 800 & 2.400 \\
\hline Kocaköy & 360 & 1.008 & 110 & 220 & 400 & 459 & 400 & 920 & 420 & 1.260 \\
\hline Kulp & 3.350 & 8.192 & 250 & 338 & 2.400 & 2.430 & 400 & 600 & 750 & 2.438 \\
\hline Lice & 2.480 & 4.908 & 820 & 1.640 & 1.480 & 1.357 & 950 & 1.900 & 1.000 & 2.500 \\
\hline Silvan & 410 & 1.161 & 333 & 833 & 925 & 1.367 & 600 & 1.470 & 2.500 & 8.175 \\
\hline Bağlar & 20 & 75 & 10 & 25 & 10 & 16 & 100 & 250 & 100 & 320 \\
\hline Kayapınar & 1.400 & 4.248 & 1.300 & 3.900 & 1.500 & 3.000 & 3.400 & 10.200 & 3.000 & 9.000 \\
\hline Sur & 225 & 1.406 & 107 & 980 & 200 & 400 & 1000 & 2.750 & 1.000 & 4.500 \\
\hline Yenişehir & 1.210 & 4.388 & 310 & 1.025 & 280 & 420 & 150 & 450 & 250 & 1.000 \\
\hline
\end{tabular}

Anonim, 2019

Dicle nehri kenarında çakıllı, kumlu arazilerde kendine özgü yöntemlerle yapılan karpuz yetiştiriciliğinin, yöre halkının ekonomik, sosyal ve kültürel yaşantısında önemli bir yeri bulunmaktadır. Birçok çiftçi geçimini karpuzdan sağlamaktadır. Karpuz yetiştiriciliğinde kullanılan güvercin gübresini temin etmek için, yörede "Boranhane" denilen ve içinde sadece güvercin yetiştirilen kerpiç odacıklar günümüzde hâlâ kullanılmaktadır. Sadece karpuz tarlalarında bulunan ve "Hülle" diye adlandırılan gölgelikler de, tarımsal bir gelenek halini almıştır. Diyarbakır karpuzu dünyaca ünlü ender tarım ürünlerimizden birisidir. Her ürünümüz de olduğu gibi Diyarbakır karpuzunun da kendine has özellikleri vardır. İlk göze çarpan özelliği iriliğidir, ikinci özelliği ise lezzetli oluşudur. Kumsal arazide yetişen karpuzların içine küçük bir çocuk sığabilir. Diyarbakır karpuzu olarak 5 tip karpuz yetiştirilir. Bunlar; Pembe, Sürme, Ferik Paşa, Beyaz Kıș ve Karakıș’tır. Ancak günümüzde sadece "Sürme" tipinin yetiştiriciliği yapılmakta olup diğer tipler artık yetiştirilemez olmuş hatta yok olma tehlikesiyle karşı karşıyadır. Yöremizde her ne kadar bu karpuzlar çeșit olarak bilinse de bunlar aslında tescilli çeşit olmayıp "populasyon" niteliğindedir. Fakat ifade kolaylığı açısından çeşit olarak anılmaktadır. Sürme çeşidi "Sürme hırsızı" adıyla da anılmaktadır. Her ne kadar meyvenin ağırlığ düşmüşse de günümüzde yetiştiriciliği yapılan tek çeşit olarak göze çarpmaktadır (Resim1.). 


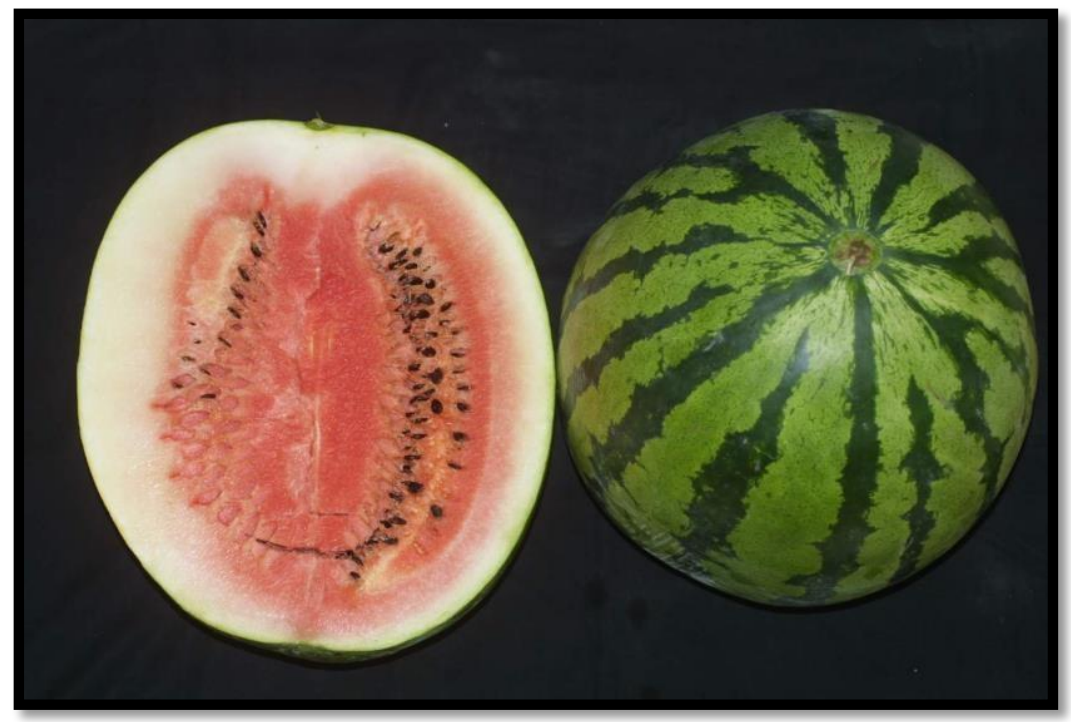

Resim 1. Diyarbakır Karpuzu Sürme Çeşidine Ait Meyveler (iç ve dış görünüş)

Çizelge 4. Diyarbakır ili Seçilmiş Ürünlerde Toplam Sebze Üretim Değerleri

\begin{tabular}{|l|r|r|}
\hline ÜRÜNLER & \multicolumn{1}{|c|}{$\begin{array}{c}\text { Ekiliș Alani } \\
\text { (da) }\end{array}$} & $\begin{array}{c}\text { Üretim } \\
\text { (ton) }\end{array}$ \\
\hline DOMATES & 28.543 & 84.652 \\
\hline PATLICAN & 7.106 & 17.438 \\
\hline KABAK & 300 & 440 \\
\hline BAMYA & 105 & 49 \\
\hline HIYAR & 9.316 & 24.109 \\
\hline BìBER & 15.104 & 22.432 \\
\hline T.SOĞAN & 1.542 & 1.433 \\
\hline KAVUN & 21.280 & 53.025 \\
\hline KARPUZ & 43.382 & 163.218 \\
\hline
\end{tabular}

Anonim, 2019

\section{DIYYARBAKIR KARPUZU YETISTTİİCİLİĞí}

Diyarbakır karpuzu, gerek kendine özgü yetiştirme tekniği ve gerekse tadı ve iriliği ile eskiden beri kendinden söz ettirmektedir. Önceki yıllarda yetiştiriciliği oldukça yaygın bir durumdayken, zaman içeresinde Diyarbakır Karpuzu olarak bilinen "Sürme", "Pembe", "Beyazkış", "Karakış" ve "Ferik Paşa" çeşitleri kaybolmaya yüz tutmuştur (Beşirli, 1991). Bu çeşitlerden sadece "Sürme", "Beyazkış", "Karakış" ve "Pembe" çeşitlerine ait bir miktar tohum bulunabilmiştir. Yıllardır ihmal edilen ve adeta yok olmaya bırakılan Diyarbakır karpuzu, eski özelliklerini de yitirmeye başlamışııı. Eskiden yapılan "kuyu karpuzculuğu" yöntemi de bugün artık uygulanmamaktadır. Önceleri 70-80 kg gelen karpuzlar bu gün en fazla 40-45 kg gelebilmektedir. Çeşitler ve yetiştirme yöntemleriyle birlikte erozyona uğrayan Diyarbakır karpuzu, aynı zamanda yetiştirme alanı ve yetiştirici bakımından da yok olmaya bırakılmıştır. Giderek azalan Diyarbakır karpuz yetiştiriciliği ne yazık ki yerini büyük ölçüde dışardan getirilen hibrit çeşitlere birakmıştır (Pirinç, 2004).

Karpuzlar zamanı geldiğinde doğrudan doğruya hazırlanan yerlere ekilmek suretiyle üç şekilde yetiştirilir (Şeniz ve ark. 1995; Günay, 1992; Beşirli, 1991; Ekinci, 1972).

\section{Sıra (Çizgi) Usulü}

Ekim mevsimi geldiğinde çeşidin gelişme kuvveti ve toprağın karakterine göre genellikle 1.5-2 metre ara ile pullukla 5-6 cm derinlikteki çizgiler (karık) açılır. Bu çizgiler içeresine hemen hemen aynı mesafe üzerinden ekim yapılır. Ekimde her ekim yerinde ileride seyreltilmek üzere 3-4 adet tohum atılır ve 
tohumların iriliklerine göre $3-5 \mathrm{~cm}$ derinlikte kalacak şekilde üzerleri mümkünse gübreli toprakla kapatılır ve hafifçe bastırılır. Tohumlarda çimlenme oranının yüksek olması için toprağın tavında olması gerekir.

\section{Ocak Usulü}

Çizgi usulündeki ölçüler dâhilinde yaklaşık 40-50 cm çapında ve $15-20 \mathrm{~cm}$ derinliğinde açılan çukurların diplerine 5-10 cm kalınlığında gübreli toprakla yataklık konarak tohumlar bunun üzerine ekilir ve üzerleri 4-5 cm derinlikte kalacak şekilde kapatılır ve hafifçe bastırılır. Bazen de açılan bu çukurlara daha önce başka yerlerde çimlendirilmiş fideler dikilerek yetiştiricilik yapılır.

\section{Kuyu Karpuzculuğu}

$\mathrm{Bu}$ metot, Dicle Nehri kıyılarında çakıllı ve milli topraklar üzerinde dünyaca meşhur iri Diyarbakır karpuzunun yetiştirildiği metottur (Resim 2.). Bu metot Dicle nehri kıyılarında çakıllı ve milli topraklar üzerine dünyaca meşhur iri Diyarbakır karpuzunun yetiştirildiği bir metottur. Ayrıca Diyarbakır ve yöresinde görülen kuru tarım şeklinde yapılan karpuz yetiştiriciliği de vardır. Bu tarz yetiştirilen karpuza Beji denir. Sulama yapılmaksızın yapılan karpuz yetiştiriciliğidir. Ancak erkencilik sağlamak, homojen üretim yapmak ve fide ile yetiştirmenin diğer avantajlarından dolayı karpuz yetiştiriciliği artık fideden yapılmaktadır. Fideliklerde yetişen fideler; 1-1,5 ay sonra fideliklerden sökülüp araziye aktarılarak asıl yerlerinde yetiştirilmektedir.

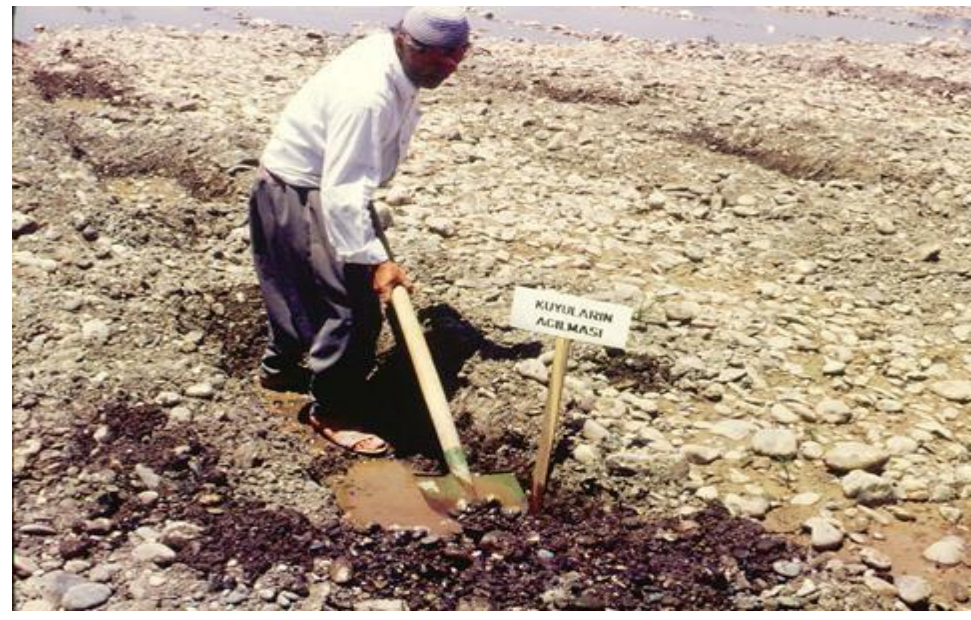

Resim 2. Diyarbakır'da Kuyu Karpuzu Yetiştiriciliğinde

\section{Kuyuların Hazırlanması}

Kuyuların açılması için bahar aylarının sonuna kadar Dicle nehrinin çekilmesi beklenir.

Nehir yetirince çekildikten sonra genellikle 15 -30 Nisan tarihleri arasında kuyu açmak üzere Dicle kenarına inilir. Günümüzde birim alandan kazanmak amaçlanmış olmalı ki kuyuların boyutları küçültülmüştür.

Kuyular, kuyu uzunluğu 150 cm kuyu genişliği ve derinliği 40-60 cm olacak şekilde hazırlanmaktadır. İki kuyu arası da $50 \mathrm{~cm}$ iki kuyu sırası arasında ise $2 \mathrm{~m}$ mesafe bırakılmaktadır. Kuyuların derinliği her ne kadar 40-60 cm arasında değişiyorsa da derinlikte amaç su seviyesine ulaşmaktır (Resim 3.). 


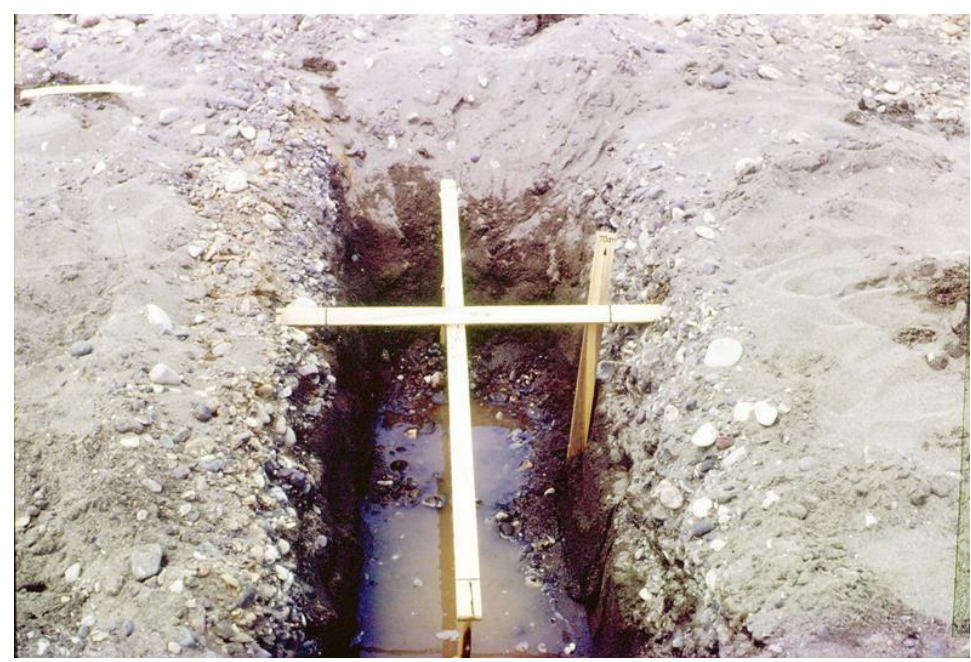

Resim 3. Diyarbakır'da Kuyu Karpuzu Yetiştiriciliği

\section{Gübreleme}

Diyarbakır karpuz yetiştiriciliğinde, yetiştirme yöntemi kadar kullanılan gübre ve gübrenin uygulama şekli de oldukça önemlidir. Karpuza tad, lezzet ve büyüklüğü sağlayan en önemli faktörün gübre olduğu söylenebilir.

Karpuzlara verilecek koyun gübresi ve güvercin gübresi kum ile karıştırılıp harç haline getirilerek verilmektedir. Yörede genel uygulama olarak; kuyu başına; $6-8 \mathrm{~kg}$. güvercin gübresi ve $20-25 \mathrm{~kg}$. koyun gübresi ve kum kullanılmaktadır. Yapılan çalışmalar gösteriyor ki karpuz bitkisine ne kadar çok güvercin gübresi verilirse karpuz meyvesi o derecede tatlı ve lezzetli olmaktadır. Ancak güvercin gübresi maliyeti artıran en büyük unsurlardan biri olduğundan dolayı üreticiler bu miktarı artıramadıkları için birçoğu kuyu başına 6 kg' in da altında güvercin gübresi vermektedir.

\section{Gübrenin Veriliș Şekli}

İlk gübreleme fide dikiminden iki gün sonra yapılmaktadır. Bu ilk gübrelemede her bir kuyu başına hazırlanan harçtan yaklaşı 2 kilogram gübre verilmektedir. Gübre karışımı, su ile kökün temas ettiği bölgeye bırakılarak suda çözünen organik maddeden bitkinin kolayca faydalanması sağlanmaktadır. Bu ilk verilen gübreye "avuç" adı verilmektedir. Birinci gübrelemeden 10 gün sonra ikinci gübreleme yapılıyor. Bu 10 gün süresince kuyu içinde bulunup da kök ile temas halinde olan su çekilmiştir. Suya ulaşıncaya kadar tekrar kazım yapılır ve çıkarılan kumlar bitkinin kök bölgesindeki daha önce verilmiş olan gübrenin üzerine bırakılır. Bu kazım esnasında suya ulaşmış halde bulunan karpuz kökleri de açı̆̆a çıkarılmış olur. İkinci gübre bu köklerin üzerine verilerek kökün sürekli olarak su ve gübre ile temas halinde olması sağlanmaktadır. Tabanda bulunan su ne kadar çekilirse kökler de beraberinde o kadar derine inmektedir. İkinci gübrelemede pratik olarak on altı kilogramlık tenekelerle her bir kuyu başına birer teneke gübre verilmektedir.

Bu gübrelemede de daha önce hazırlanmış bulunan harç kullanılmaktadır. Bu gübrelemeye "ilk taam" adı verilmektedir. Üçüncü gübrelemenin zamanı bitkinin gelişimine bakılarak tayin edilmektedir. Eğer bitki çabuk gelişip kendini toparlamışsa ikinci gübrelemede 12 - 15 gün sonra üçüncü gübreleme yapılmaktadır. Eğer bitkilerin gelişimi iyi değilse gelişimlerini tamamlamaları beklenerek üçüncü gübre, ikinci gübrelemeden 20 - 25 gün sonra verilmektedir. Gecikme istenmeyen bir durum olup bu şartlarda hasatta da en az 10 günlük gecikme söz konusu olmaktadır. Üçüncü gübrelemede önce de ikinci gübreleme de olduğu gibi tekrar taban suyuna ulaşılmaktadır. Üçüncü gübreleme esnasında yalnızca kuyunun ortası boş kalmıştır ve artık kökler karşılıklı olarak burada buluştuklarından gübre ayrı ayrı kuyu başlarına değil kuyunun tam ortasına konmaktadır. Üçüncü gübrelemede önceki teneke hesabıyla bir teneke gübre, kuyunun ortasında su ile köklerin temas ettiği yere konmaktadır. Bu gübrelemeye "son taçim” adı verilmektedir. Böylece gübreleme işlemi tamamlanmış olmaktadır.

\section{Hasat}

Diyarbakır karpuzunda hasat ağustos ayının sonlarında başlamakta ve eylül ayının sonuna kadar sürebilmektedir. Hasatta irilik başta olmak üzere çeşit özelliğine göre olgunluk kriterleri dikkate alınarak 
yapılmakta olup festival için yetiştirilen karpuzlar koruma altına alınarak yarışmaya kadar arazide muhafaza edilir.

Diyarbakır karpuz tiplerinden Sürme tipinin yetiştiriciliğinin, 1990 yıllara kadar kadar kuyu karpuzculuğu şeklinde yetiştiriciliği yapılmakta iken Dicle Nehir debisinin nisan aylarından itibaren düzenli olmamasından dolayı bu yöntemden vaz geçilmiștir. Çünkü açılan kuyular zamanla Nehir suyunun altında kalmaktadır. Günümüzde normal yetiştirme yöntemine göre 45-55 kg ağırlıkta karpuzlara ulaşılabilmektedir. Bu ağırlıktaki meyvelere ulaşmak her zaman için mümkün olmamakta ve zaman zaman daha düşük ağırlıktaki meyvelere yani $30-35 \mathrm{~kg}$ 'lk ürünlere ancak ulaşllabilmektedir. $\mathrm{Bu}$ durum ancak festivallere yönelik yapılan üretimde gerçekleşmektedir. Çiftçi karpuz yarışması ve festivale katılabilmek için şartlarını zorlayarak karpuz yetiştiriciliğini gerçekleştirmektedir. Yapılan bu yetiştirme şeklinde güvercin gübresi kullanılmamakta ve ticari gübre ile geleneksel yetiştiriciliğin uygulanmadığı ocak usulü ile yetiştiricilik yapılmaktadır.

\section{SALNAMALERDE DIYYARBAKIR KARPUZU}

Diyarbakır karpuzunun yetiştiriciliğginin anlatıldığı "Diyarbakır Salnamaleri”" adlı eserde ilin tarımsal yapısı hakkında da bilgi verilmektedir. Karpuzla birlikte "Diyarbakır kavunu" olarak anılan farklı kışılı kavun tiplerinin karpuz yetiştiriciliği ile birlikte anılması kavunun da karpuz kadar yaygın ve önemli olduğunu göstermektedir (Anonim, 1999). İlin geçmiş dönemdeki karpuz yetiştiriciliği bu eserde detaylı anlatılmış ve aşağıda orijinal haliyle her hangi bir değişiklik yapılmadan verilmiştir;

\section{Kavun-Karpuz}

Kavun ve karpuz peji ve sulu olmak üzere iki nevi olup sulusu sulaklarda ve nehr-i Dicle'nin etraf ve adalarinda husule gelmektedir. Nehri cinsinin cesamet ve lezzetinin her yerde şöhreti olmakla bazı mahallerde dahi bu cinsten yetiştirilmek üzere vuku bulan talebe mebni suret-i zer'i hakkinda yapllan tarife geçen sene Ticaret Nezaret-i Celilesi'ne takdim kalınmış ve Ziraat gazetesiyle neşr olunmuş idi. Fayda me'mülüyle bir ayn atide derc olundu.

\section{Tarife}

Diyarbekir vilayetinin kavun ve karpuzu gibi Memalik-i Şahane'nin hiçbir tarafinda görülmemiştir. Bu vilayette olan kavun ve karpuzun kit'ast gayet büyük olduğu gibi ziyade tatlddr.

Kıt'ası ol kadar büyük olur ki, iki karpuzu bir ester ancak götürebilir.

\section{Bu Kavun ve Karpuzlarin Suret-i Zer'i:}

Karpuz ve kavun dikilecek mahal nehir kenarında kumlu ve alt sulu olmalıdır. Böyle mahallerde bel ile kuyular kazıllır ve kuyular ol derece derinlikte kazllır ki altından bir karıştan nihayet dört parmağa kadar su zahir olmak lazımdır. Kuyuların tülü iki buçuk zira-ı a 'şari ve arzı bir zira olacaktır.

Bu kuyuların kazılmasından hasıl olacak kum kuyunun dışarı tarafina yığıllı ve kuyuların şu tülleri itibartyla her kuyunun derinliğinde olan iki başında iki batman -ki altı okka itibar olunur-kadar yasdlk tabir olunur kum bırakılır. Ondan sonra bu yasdıklara birer tane çillenmiş tohum dikilir.

Bu yastıklara birer tohum dikilmesi bir ihtiyat içindir ki şayet bu kuyularda suyun çekilmesi me'mul olunur ise ol vakit şu yastıklara bu çillenmiş tohum dikilmeyip bir hafta kadar kuyular hali üzerine bırakilacak ve hafta başında kuyuların suyu her ne raddeye inmiş ise o itibarla çillenmiş olan çekirdek dikilecektir. Şu kadar ki su tamamıyla çekilmemiş olur ise tekrar kazılıp suyu tâhire çıkarmak lazımdır ve o su bir hafta zarfinda ne kadar eksileceği ve kuyunun neresine ineceği tahmin olunduktan sonra suyun ineceği mahalle aşağıda tarif olunduğu veçhile çillendirilmiş olan tohum dikilecektir.

\section{Tohumların Çillendirilmesi}

Karpuz tohumundan lüzumu miktarını bir torbada akşam suya koyup sabahısı çıkarmalı ve nemli bir mahalli dört parmak derinliğinde kazıp bu kazılan yere tohumları kalınca serpmeli ve üzerine toprak çekmelidir. Bu tohumlar altı gün sonra dikilmeye elverişli bir surette çillenmiş olur. Bu çillerin baş taraflarındaki çekirdek kabuğunu tamamıyla atmamış olmak makbul ise de şu çekirdek kabuğunu atmış olsa da beis yoktur. Çiller zuhurundan bir inci ve nihayet üçüncü gününe kadar dikilebilir ise de dördüncü gününe kalır ise artık kartlaşıp yaprakları birbirinden ayrllacağı cihetle bunları atıp yeniden başka çekirdekleri çillendirmek iktiza eder. Binaenaleyh kazılan kuyular nisbetinde tohum çillendirmek lazım gelir.

Çillenmiş̧ çekirdekler şu suretle dikili: Kuyulardaki suyun ulaş̧tı̆̆ mahalden suyun ta kenarına dikilir. $O$ halde çekirdeklerin incecik saçaklarının uçları suda kalmış bulunur. Çillenmiş çekirdekler bu suretle 
suyun ağzına kondukta bir avuç sulu kum çilin kökü üzerine konulup hafifçe bastırılacaktır. Bir gün sonra eski yanmış gübreden bir miktar gübre tohumunun köküne konmuş olan kumun üstün çıkarıp atmalı ve yerine ihtiyat olarak çillendirilmiş olan çillerden evvelce tarif olunduğu vechile dikilmelidir.

Çiller sararmayı da yeşil rengi zayi etmemiş ise tutmuş olduğu malum olur ve o halde kuyunun ortasında olan yaş kumları kuyunun iki başına dikilmiş olan çillerin etrafina yı̆̆ıp bir haftada böyle bırakılır. Hafta geçtikte kuyunun ortasında boş kalmış olan zira kadar mahal yine haliyle bırakılıp yani kum doldurulup bırakmalı ve kuyunun tülünde olan iki tarafı kazıp suyu kuyudan zahire çıkarmalıdır. Ondan sonra birer buçuk okka kadar güvercin gübresini çillerin alt tarafında kalmış olan suya doğru dökmelidir. Bunun üzerine üç rub’u sarl ve güzel kum ve bir rub'u yanmış gübreyi birbirine karlştırarak sonra da kuyunun iki ucunun yanı başından kazılmış ve suları oraya alınmış olan sulu yerlere döküp doldurmalıdır.

Bundan da bir hafta geçer geçemez kuyunun ortasında hali üzer kalan bir zira'mahal bu sırada kazılıp ondan çıkan nemli kumun nisfiyet üzere köklerin bulundukları taraflara verilir ve o kazılan mahal ise tabii sulu ve boş kalır ve bu boş yere iki okka miktarl güvercin gübresi döküp evvelki gibi sarı kum ve yanmış gübre doldurmalı ve bir hafta da bu halde birakmall. Ondan sonra en evvel kuyular kazılıp içinden çıkan ve kuyunun iki tarafında bırakılmış olan kumları kuyular düzeltinceye kadar kuyulara doldurmalıdır. Işste bu vakte kadar kökler yetişmiş olur.

Bu suretle dikilen bostandan alınan karpuz ve kavunun taamı pek lezzetli olup kıt'aları ol kadar olur ki bazan kırk elli kıyye ve daha ziyade ă̆ırlıkta karpuz ve yirmi kıyyeden ă̆ır kavun hasıl olur.

\section{Sebze}

Sebzenin bu vilayette her nevi husule getirilir: Patlican, bamya, kabak, bakla, hiyar, acur, lspanak, marul, pancar, şalgam, havuç, turp, domates, patates, fasulye, lobya, nane, soğan, sarımsak, maydanoz her mahalde ve pirasa, lahana, salatalı, enginar bazl yerlerde zer olunur. Hindiba, semizotu, kenger, uçkun, bă̆, ebegümeci, yer elması hüda-yı nabittir. Mardin'de a'la keme hasıl olur.

\section{SONUÇ VE ÖNERILER}

Diyarbakır karpuzu dünyaca tanınmakla birlikte ilin folklorik, ekonomik ve kültürel yapısında önemli bir konuma sahiptir. Karpuzun günümüze kadar gelmiş olması da bunun bir kanıtı sayılabilir. Ancak geçmişte beş tip olarak bilinen Diyarbakır karpuzundan bu gün sadece Sürme tipi kalmıştır. Bu tip de yabancı tozlanma, eksik ve yetersiz yetiştiricilikten dolayı eski özelliğini yitirmiştir. Ayrıca bölgeye girmiş olan hibrit çeşitlerle rekabet edememesi bu çeşidin giderek kaybolmasına neden olmaktadır.

Önceki yıllarda yetiştiriciliği yoğun bir şekilde yapılmasına rağmen, son yıllarda yetiştiricilik oldukça sınırlı bir alanda gerçekleştirilmektedir. Diyarbakır karpuzunun bu kadar dar alanda yapılması ve eski özelliklerinin kaybetmesinin temel nedenleri arasında şu faktörler göze çarpmaktadır;

- Son yıllarda Dicle Nehrinin ekolojisinin bozulması ve nehrin kenarlarında kum ocaklarının yapılmasıyla karpuz alanlarının azalması,

- Eskiden yapılan kuyu karpuzculuğunun artık yapılamaması,

- Diyarbakır karpuzunun bölgeye giren hibrit tohumlarla rekabet edemeyecek durumda olmas1, - Hastalık ve zararlıların ortaya çıkması,

- Üretim maliyetinin artması yetiştiricilikte büyük sorunlara neden olurken üreticilere gerekli olanakların sağlanmaması gibi nedenler de etkili olmuştur.

Bu gün Diyarbakır karpuz üretiminin eskisi kadar canlı bir şekilde yapılmasını beklemek zor olmakla birlikte, karpuz üretimine bir nebze olsun canlılık getirmek için bazı elverişsiz şartların da ortadan kaldırılması sağlanmalıdır. Bu olumsuzlukların ortadan kaldırılması için;

- Çiftçilerin karpuz üretimine teşviki için gerekli desteklemeler yapılmalıdır.

- Çiftçilere gerekli eğitici ve teknik bilgiler verilmelidir.

- Tarım il müdürlüğü ile çiftçiler sürekli bilgi alış verişinde bulunmalı ve bunu yanında festivaller ile çiftçiyi özendirici ödüller verilmedir.

- Bütün bunlara ek olarak üreticilerin sorunuyla yakından ilgilenilmelidir.

- Diyarbakır karpuzunun üretiminin yapıldığ 1 yerler koruma ve kontrol altına alınmalı ve bu yerlerde karpuz üretimine olumsuz etki yapacak her türlü faaliyetlere engel olunmalıdır.

- Diyarbakır karpuzunun hibrit çeşitlerin gölgesinden kurtarılması için olabildiğince her türlü olanak ve imkân oluşturulmalıdır.

- Hastalık ve zararlılarla yeteri derecede mücadele sağlanmalıdır

Ayrıca son yıllarda ortaya çıkan aşılı karpuz üretimi yaygın bir hale getirilmeli, çünkü aşılı karpuz ile hem hastalığa (Fusarium) dayanım sağlanmış olunacak hem de bu tipin korunarak yetiştiriciliğine imkân sağlanmış olunacaktır. 
Dicle Nehri ekolojisinin karpuz üretimine uygun hale getirilmelidir.

Bilimsel ve teknik bir eksiklik olarak değerlendirilebilecek önemli bir konuda bu materyalin ıslahına başlanılmalı ve tohumları koruma altına alınmalıdır.

Kaybolan diğer çeşitlere ait tohumların temini için köylere teknik gezi yapılmalıdır.

Diyarbakır karpuzu ile ilgili bir diğer önemli eksiklik ise çeşitleri tanıtıcı bir kitap veya broşürün olmayışıdır. Hazırlanan bu çalışmanın; Diyarbakır karpuzunun tanıtımına bir katkı sağlayacağı düşünülmektedir.

\section{KAYNAKLAR}

Anonim, (1999). Diyarbakır Salnameleri, C.3.

Anonim, (2019). TUİK, Web: https://biruni.tuik.gov.tr/bolgeselistatistik

Beşirli, G. (1991). Diyarbakır Karpuzu, Tarım Orman ve Köy İşleri Bakanlığı Güneydoğu Anadolu Tarımsal Araştırma Enstitüsü Müdürlüğü, Yayın No:2, Diyarbakır.

Beysanoğlu, Ş. (1972). Kara-Amid Tarih, Turizm, Edebiyat Dergisi sayı:8, Cilt II.

Decoteau, DD. (2000). Vegetable Crops, Prentice Hall, Upper Saddle River, NJ.

Ekinci, S. (1972). Özel Sebzecilik. Ahmet Sait Matbaas1, İstanbul, 231 s.

Günay, A. (1992). Genel Sebzecilik. Cilt 1. Ankara Üniversitesi Ziraat Fakültesi, s:1-7.

Kütevin, Z. ve Türkeş, T. (1985). Sebzecilik. Genel Sebze Tarımı Prensipleri ve Pratik Sebzecilik Yöntemleri, Inkilap Kitabevi, İstanbul, 309s.

Mohr, HC. (1986). Watermelon Breeding. In: Breeding Vegetable Crops (Bassett MJ (ed)). Part 2 (pp. 37-66). AVI Publishing Co., Inc, Westport, CT.

Pirinç, V. (2004). Diyarbakır Karpuzunun (Citrullus lanatus cv. "Sürme”) Mikroçoğaltılması. (Doktora Tezi) D.Ü. Fen Bilimleri Enstitüsü Biyoloji Anabilim Dalı, Diyarbakır

Sauer, J.D. (1993). Historical Geography of Crop Plants-a selected roster. CRC Pres, Boca Ralon Florida.

Seçmen, Ö., Gemici, Y., Görk, G., Bekàt, L. ve Leblebici, E. (2000). Tohumlu Bitkiler Sistematiği Ders Kitabı. Ege Üniversitesi Fen Fakültesi Kitaplar Serisi No: 116, 211-212. İzmir

Şeniz, V., Özgür, M., Sivritepe, Ö. ve Özer, M.H. (1995). Sebzecilik. Açıöğretim Fakültesi Yayınları No:458,1-21.

Van Wyk, B. \& Gericke, N. (2000). People's Plants- a Guide to Useful Plants of Southern Africa. Briza Publications, Preloria.

Yaltırık, F. ve Efe, A. (1989). Otsu Bitkiler Sistematiği Ders Kitabı. İstanbul Üniversitesi Yayın No: $3568,427$. 